Available online on 15.03.2020 at http://jddtonline.info
Open Access to Pharmaceutical and Medical Research
unrestricted non-commercial use, provided the original work is properly cited

open Access

Research Article

\title{
Hematological Changes During All trimesters in Normal Pregnancy
}

\author{
Asaad Ma. Babker, Elkhansa Osama Di Elnaim
}

Department of Hematology and Immunohematology, College of Medical Laboratory Science, Sudan University of Science and Technol ogy, Khartoum, Sudan

\begin{abstract}
Aim: The objective of the study is to evaluate the normal physiological changes in values of major hematological parameters occur during the normal pregnancy

Method: Blood samples ( $5 \mathrm{ml}$ EDTA) were taken voluntarily after consent obtained from from 50 healthy pregnant women from 20 to 40 year s old who presented themselves at Khartoum teaching during their regularly follow-up. Questionnaires and direct interview were used to collect demographic and clinical data. CBC and part differential (WBC, RBC, Hb, PCV, and platelets), were measured by Sysmex and the plasma clotting time PT and PTT were measured by coagulometer.
\end{abstract}

Results: W'BCs mean value was 7.580 cell/mm3, RBCs mean value was 4.1 x 1012/L, Hb mean value was $11.79 \mathrm{~g} / \mathrm{dL}$, Platelets mean value was $256 \times 10^{9} / \mathrm{L}$, PT mean value of the study group was 13.40 seconds and PTT mean value was 36.20 seconds.

Conclusion: It can be concluded that no statistical significance in RBCs, HB, platelets. PT and PTT between pregnant women in the three different trimesters while white WBCs count showed different decreased but not statistical significant among the three groups, the highest value was round in the second group followed by the third group and the lowest value found in the first group.

Keywords: Normal pregnancy, Hematological Changes, Pregnancy trimesters

Article Info: Received 04 Jan 2020; Review Completed 06 Feb 2020; $\quad$ Accepted 14 Feb 2020; Available online 15 March 2020

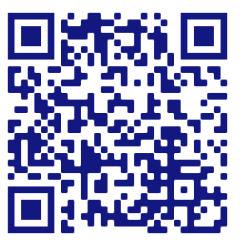

\section{Cite this article as:}

Babker AM, Elnaim EOD, Hematological Changes During All trimesters in Normal Pregnancy, Journal of Drug Delivery and Therapeutics. 2020; 10(2):1-4 http://dx.doi.org/10.22270/jddt.v10i2.3958

\section{*Address for Correspondence:}

Asaad Ma. Babker, Department of Hematology and Immunohematology, College of Medical Laboratory Science, Sudan University of Science and Technology, Khartoum, Sudan

\section{INTRODUCTION:}

During pregnancy, the pregnant mother undergoes significant anatomical and physiological changes in order to nurture and accommodate the developing foetus. These changes begin after conception and affect every organ system in the body (1). In a pregnancy, there can be multiple gestations, as in the case of twins or triplets. Childbirth usually occurs about 38 weeks after conception; in women who have a menstrual cycle length of four weeks, this is approximately 40 weeks from the last normal menstrual period (2). Normal pregnancy is characterized by profound changes in almost every organ system to accommodate the growing and developing fetoplacental unit. The major hematologic changes during pregnancy include expanded plasma volume, physiologic anemia, mild neutrophilia in some individuals, and a mildly prothrombotic state. The clinician must be able to distinguish these anticipated physiologic changes from those caused by pregnancy-related complications (3). Some of these changes are well-known, such as the reduction in hematocrit and hemoglobin levels, which is termed physiological or dilutional anemia of pregnancy. Similarly, the renal changes leading to lower creatinine values in pregnancy are well-described and a "normal" serum creatinine value of $1.0 \mathrm{mg} / \mathrm{dL}$ in a nonpregnant woman is immediately recognized as elevated in the pregnant woman (4). These changes are essential to help the woman to adapt to the pregnant state and to aid fetal growth and survival. The hematologic system must adapt in a number of ways, such as provision of vitamins and minerals for fetal Hematopoiesis (iron, vitamin B12, folic acid), which can exacerbate maternal anemia, and preparation for bleeding at delivery, which requires enhanced hemostatic function (5) .The most significant hematological changes are physiologic anemia, neutrophilia, mild thrombocytopenia, increased procoagulants factors, and diminished fibrinolysis (6). Plasma levels of factors VII, VIII, IX, XII, together with fibrinogen and fibrin degradation products, increase during pregnancy. Pregnancy is associated with enhanced platelet turnover (7). Coagulation factors remain elevated for up to 8-12 weeks post-partum and assays for them may be falsely negative during this 
period. Thus, pregnancy is a prothrombotic state. In pregnancy, aPTT is usually shortened, by up to $4 \mathrm{~s}$ in the third trimester, largely due to the hormonally influenced increase in factor VIII. However, no marked changes in PT or TT occur (8). Thrombocytopenia (platelets $100 \times 109 / 1$ ) occurs in $0.8-0.9 \%$ of normal pregnant women, while increases in platelet factor and thromboglobulin suggest elevated platelet activation and consumption (9). Normal pregnancy is characterized by many physiological changes in almost every organ system to accommodate the growing and developing fetoplacental unit. The aim of this study to evaluate the normal physiological changes in values of major hematological parameters occur during the normal pregnancy.

\section{MATERIAL AND METHOD}

This is cross-sectional descriptive and analytical study conducted at Khartoum teaching hospital department of gynecology and obstetrics. The study population comprised fifty apparently healthy pregnant women attending for monitoring of their pregnancy aged between 20 and 40 years were recruited into the study. Only women, whose last menstrual date, HCG and ultrasound determinations were congruent were enrolled in this study. No subject had a history disease, vaginal bleeding during course of the present pregnancy or received any form of blood transfusion within the past seven months. Subjects were divided into three pregnancy groups, depending on the duration of pregnancy in to the first trimester, second trimester and the third trimester of pregnancy. We used reference values of the health status of normal pregnant women as controls and comparison. Informed consent was obtained from each subject before recruitment into the study. A meeting interview was used for filling in a questionnaire which designated for matching the study need and all interviews were conducted face to face by the researcher herself. About five $\mathrm{ml}$ of venous blood divided in tow vacationer tubes two and half $\mathrm{ml}$ of whole blood in $\mathrm{K} 2$ ethylene diamine tetra acetic acid (EDTA) for complete blood counts and other (two and half $\mathrm{ml}$ ) of whole blood with 1:9 ratio of tri sodium citrate were collected and then centrifuged to take platelets poor plasma (PPP) to perform PT and APTT. All blood samples were collected between 9am and 12noon each day and analyzed within 2 hours of collection. Hematological and coagulation analysis were done at room temperature $\left(27.5 \pm 0.5^{\circ} \mathrm{C}\right)$. Sysmex KX-21 (hematology analyzer) was used for complete blood counts especially (Hb, RBCs. TWBCs and PLTs) were considered to be measured directly three hydraulic sub systems were used to determine the hemogram; the WBC channel, the red cell, plat channel and a sprite $\mathrm{Hb}$ channel. All automated analysis was done after proper bar- coding to ease identification. Prothrombin time (PT) and Activated Partial Thromboplastin Time (APTT) was determined by manual method which base on fibrin clot formation in glass tube. The test measures the plasma clotting time in addition of tissue extract thromboplastin (PT) and activation of contact factors (PTT) depend on normal value of PT (12-16 second) normal value of APTT (20-40 second). Data were entered and analyzed by SPSS prograrmme. All demographic data of the study population were presented as mean \pm SD in the text and Odds Ratio was used for detecting the power of relationship between the determinant and the outcome and 95\% confidence interval was calculated.

\section{RESULTS:}

Enrolled in this study fifty apparently healthy pregnant women attending Khartoum teaching department of gynecology and obstetrics. According to the age, the study group was divided into four groups first percent, the highest percent (48\%) of the pregnant women were between the age of 2630 , second percent (28\%) between the age of $20-25$, third percent $(22 \%)$ between the age of $31-35$ and fourth showed lowest percent $4 \%$ in the age above 35 years (Table I). Also according to the gestation period time divided into three groups, $30 \%$ in their first trimester, $32 \%$ in their second trimester and $38 \%$ in third trimester (Table II). The haematological parameters were represented as follow: W'BCs mean value was 7.580 cell/mm3, RBCs mean value was $4.1 \times 10^{12} / \mathrm{L}, \mathrm{Hb}$ mean value was $11.79 \mathrm{~g} / \mathrm{dL}$, Platelets mean value was $256 \times 10^{9} / \mathrm{L}$, PT mean value of the study group was 13.40 seconds and PTT mean value was 36.20 seconds (Table III).

Table I: Show distribution of study group according to age:

\begin{tabular}{|l|l|l|}
\hline Age group & Frequency & Percent \\
\hline $20-25$ & 13 & 26.0 \\
\hline $28-30$ & 24 & 48.0 \\
\hline $31-35$ & 11 & 22.0 \\
\hline$>35$ & 2 & 4.0 \\
\hline Total & 50 & 100.0 \\
\hline
\end{tabular}

Table II: Show distribution of study group according to trimesters:

\begin{tabular}{|c|c|c|}
\hline Trimester & Frequency & Percent \\
\hline First & 15 & 30.0 \\
\hline Second & 16 & 32.0 \\
\hline Third & 19 & 38.0 \\
\hline Total & 50 & 100.0 \\
\hline
\end{tabular}

Table III: Show Statistical Result of cases in three trimesters:

\begin{tabular}{|c|c|c|c|c|c|c|c|}
\hline \multirow[t]{2}{*}{$\begin{array}{l}\text { Trimester } \\
\text { Parameters }\end{array}$} & Trimester & $\begin{array}{l}2^{\text {nd }} \\
\text { Trimester }\end{array}$ & $\begin{array}{l}3^{\text {rd }} \\
\text { Trimester }\end{array}$ & \multirow[t]{2}{*}{$\begin{array}{l}\text { Normal } \\
\text { Range }\end{array}$} & \multirow[t]{2}{*}{$\begin{array}{l}\text { Study } \\
\text { Range }\end{array}$} & \multirow[t]{2}{*}{$\begin{array}{l}\text { Normal } \\
\text { Mean }\end{array}$} & \multirow[t]{2}{*}{ Sig } \\
\hline & Mean & Mean & Mean & & & & \\
\hline WBC X $10^{9} . / \mathrm{L}$ & $6.3467 \pm 1.76022$ & $8.5188 \pm 1.72326$ & $7.7632 \pm 2.05189$ & $4.0-11.0$ & $3.50-12.00$ & 7000 & 0.008 \\
\hline $\mathrm{RBC} \times 10^{12} / \mathrm{L}$ & $4.3087 \pm 0.49578$ & $4.0619 \pm .55242$ & $4.0111 \pm 0.48283$ & $3.25-5.76$ & $3.9-5.6$ & 4.7500 & 0.220 \\
\hline $\mathrm{Hb} \times \mathrm{g} / \mathrm{dL}$ & $12.2133+.62663$ & $11.6813 \pm 1.87979$ & $11.5474 \pm 1.31714$ & $6.20-14.00$ & $11.5-15.5$ & 13.5 & 0.359 \\
\hline Plate $10^{9} / \mathrm{L}$ & 255.0741 .844 & $257.81+37.837$ & $255.84 \pm 70.507$ & $146-400$ & $150-400$ & 256.24 & 0.989 \\
\hline $\mathrm{PT} / \mathrm{sec}$ & $13.13+.990$ & $13.44 \pm .512$ & $13.58+.961$ & $11-15$ & $11-16$ & 13.5 & 0.321 \\
\hline PIT / sec & $34.13+5.817$ & $37.69+5.351$ & $36.58+4.670$ & $25-46$ & $30-40$ & 35 & 0.168 \\
\hline
\end{tabular}




\section{DISCUSSION}

In current study we evaluated the normal physiological changes to some of the basic hematological parameters during all trimesters of pregnancy relate to. Oure study showed no clinically significant differences between red blood cells (RBCs) and hemoglobin ( $\mathrm{Hb})$ when they compared to normal value. no any significant differences among the three trimesters groups of subjects and found with normal value, this finding supported that during pregnancy, the total blood volume increases by about 1.5 liters, mainly to supply the demands of the new vascular bed and to compensate for blood loss occurring at delivery $(8,9)$. Another reason for normal red blood cells and hemoglobin during normal pregnancy that, all women under folic acid and iron. The total white blood cells (WBCs) count showed different decreased but not statistically significant among the three groups, the highest value was round in the second group followed by the third group and the lowest value found in the first group. This finding was contradictory that white blood cell count is increased in pregnancy with the lower limit of the reference range being typically 6 , $000 /$ cumm.Leucocytosis, occurring during pregnancy is due to the physiologic stress induced by the pregnant state (10). Also, this finding contradictory with smellier study done by Li. et al., among pregnant women and concluded that there was no significant difference of hemogram changes (11). The present study showed normal Platelets in vast majority of women in all trimesters, Similar results of this finding is agree with another similar studies done by Huda.et.al, among Sudanese women were found that was no significant value among pregnant women in platelets count (12).Also this study another done by Amah, et al., among Nigerian women were found that platelets not found to show any significant differences amongst the three groups of subjects (13). Also, our finding disagree with many studies were noticed by Akinbami et al., 14, and Akingbola et al., 15 and Azab et al., 16 who reported a gradual reduction in PLT count as pregnancy advanced. Also our finding agree with another study done Patrick, etal., concluded that pregnancy in women alters hematological indices such as PCV, hemoglobin, lymphocyte, and platelet counts and that during normal pregnancy (17). The result of the present study reveals that prothrombin time and partial thromboplastin time showed no statistically significant difference and this indicates that pregnancy is not likely to have any adverse effect on these parameters. This result is consistent with an earlier report by Asaad and Fathelrahman were found that Prothrombin time and partial thromboplastin remains unchanged among pregnant women (18). Also this result is consistent with a study report by Avwioro et al., who recorded no change in the mean prothrombin time values among pregnant women (19).Also our result disagree by different studies found that there were prolonged PT and APTT and statistical significant among pregnant females $(14,20,21)$. Hematological parameters are the routinely performed investigations during pregnancy and after delivery. Thus, it is important to know the normal variation in all the parameters throughout the pregnancy and puerperium and reason behind them (22). our study has some limitations, such as the relatively small number of subjects. Our finding on these results must be determined in further large controlled studies Also, another limitation in our study it should including other biomarkers, such as fibrinogen level, differential white blood cell and iron profiles.

\section{CONCLUSION:}

We concluded that that pregnancy in women did not alters in finding of RBCs, HB, platelets, PT and PTT and no significant change among Sudanese pregnant women. But white WBCs count showed different decreased but not statistically significant among the three groups, the highest value was round in the second group followed by the third group and the lowest value found in the first group.

\section{Acknowledgments:}

I would like to thank all the pregnant women involved in the study and special thanks to the staff of Khartoum teaching hospital department of gynecology and obstetrics and especial thank to the staff of medical laboratory in Khartoum teaching hospital.

\section{Competing interests:}

The authors declare that they have no competing interest

\section{REFERENCES:}

1- Soma-Pillay P, Nelson-Piercy C, Tolppanen H, Mebazaa A.

Physiological changes in pregnancy. Cardiovasc J Afr.

2016;27(2):89-94. doi:10.5830/CVJA-2016-021.

2- Boundless. "Introduction to Pregnancy and Human

Development." Boundless Anatomy and Physiology. Boundless, 05

Aug. 2015. Retrieved 28 Sep. 2015

3- Bauer, K. A., \& Tirnauer, J. S. (2018). Maternal adaptations to pregnancy: Hematologic changes. UpToDate.

4- Cunningham FG. Normal reference ranges for laboratory values in pregnancy. UpToDate. 2014.

5- Kraemer, Klaus, and Michael B. Zimmermann, eds. Nutritional anemia. Basel: Sight and Life press, 2007.

6- Paidas, Michael J., and Nazli Hossain. "Hematologic changes in pregnancy."Hemostasis and thrombosis in obstetrics and gynecology UK: Wiley-Blackwell(2011): 1-11.

7- Prisco, Domenico, Gabriele Ciuti, and Michela Falciani. "Hemostatic changes in normal pregnancy." Hematology Meeting Reports (formerly Haematologica Reports). 2009; 1(10).

8- Ramsay Margaret. Normal hematological changes during pregnancy and the puerperium. In: Pavord S, Hunt B, editors. The obstetric hematology manual. Cambridge: Cambridge University Press; 2010. pp. 1-11

9-Kjell H, Svendsen E, and Abildgaard U. "The HELLP syndrome: clinical issues and management. A review." BMC pregnancy and childbirth 2009; 9(1):8.

10- Chandra S, Tripathi AK, Mishra S, Amzarul M, Vaish AK. Physiological Changes in Hematological Parameters During Pregnancy. Indian Journal of Hematology \& Blood Transfusion. 2012; 28(3):144-146. doi:10.1007/s12288-012-0175-6.

11- Li H., et al. "[Correlation of hemogram changes during pregnancy of healthy women with postpartum blood transfusion]." Zhongguo shi yan xue ye xue za zhi/Zhongguo bing li sheng li xue hui= Journal of experimental hematology/Chinese Association of Pathophysiology 2012; 20.5:1240-1242.

12- Babiker HI., Hiba AA, and Sana E. Abdalla. "Prothrombin Time, Activated partial Thromboplastin Time and Platelets Count in Pregnant Females and Postpartum Period with Deep Venous Thrombosis." International Journal of Hematological Disorders 2014; 1(1):41-44

13- Amah-Tariah F. S., Ojeka SO, and Dapper DV. "Haematological values in pregnant women in Port Harcourt, Nigeria II: Serum iron and transferrin, total and unsaturated iron binding capacity and some red cell and platelet indices." (2014).

14- Akinbami A. A., Ajibola S. O., Rabiu K. A., Adewunmi A. A., Dosunmu A. O., Adediran A., Osunkalu V. O., Osikomaiya B. I., and Ismail K. A. Hematological profile of normal pregnant women in Lagos, Nigeria. Inter. J. Women Health, 2013; 5:227-232.

15- Akingbola T., Adewole I. F., Adesina O. A., Afolabi K. A., Fehintola F. A., Bamgboye E. A., Aken'ova Y. A., Shokunbi W. A., Anwo J. A., and 
Nwegbu M. M. Haematological Profile of healthy pregnant women in Ibadan, south western Nigeria. J. Obstet. Gynaecol., 2006; 26(8):763769.

16- Azab, E.A., Albasha, M.O. and Elhemady, S.Y., Haematological parameters in pregnant women attended antenatal care at sabratha teaching hospital in Northwest, Libya. American Journal of Laboratory Medicine, 2017; 2(4):60.

17- Boehlen F, Hohlfeld P, Extermann P et al. Plate let count atterm pregnancy are appraisal of the threshold. Obstet Gynecol 2000; 95:29-33.

18- Babker, Asaad Mohammed Ahmed Abd Allah, and Fath EIrahman Mahdi Hassan Gameel. "Molecular Characterization of Prothrombin G20210A gene Mutations In pregnant Sudanese women with spontaneous recurrent abortions."Rawal Medical Journal 2015; 40(2):207-209.
19- Avwioro OG, Ezeobi JO, Oduola T, Fakunle OO., Prothrombin time and Activated Partial Thromboplastin time in Pregnant Women in Southern Nigeria. J App Pharm Sci. 2013; 3(06):179-181.

20- Cerneca F, Ricci G, Simeone R, et al 'Coagulation and fibrinolysis changes in normal pregnancy. Increased levels of procoagulants and reduced levels of inhibitors during pregnancy induce a

hypercoagulable state, combined with a reactive fibrinolysis' Eur J Obstet Gynecol Reprod Biol. 1997; 73(1):31-6.

21- Erhabor, 0., et al. "Some hemostatic parameters in women with obstetric hemorrhage in Sokoto, Nigeria." International journal of women's health 2013; 5:285.

22- Kaur S, Khan S, Nigam A. Hematological profile and pregnancy: a review. Int J Adv Med 2014; 1:68-70. 